\title{
Green Supplier Selection in New Era for Sustainability: A Novel Method for Integrating Big Data Analytics and a Hybrid Fuzzy Multi-Criteria Decision Making
}

Abdullah YILDIZBASI ( $\square$ abdullahyildizbasi@gmail.com )

Ankara Yildirim Beyazit Universitesi https://orcid.org/0000-0001-8104-3392

Yağmur ARIOZ

Ankara Yildirim Beyazit University: Ankara Yildirim Beyazit Universitesi

\section{Research Article}

Keywords: Green Supplier Selection, Big Data, Fuzzy Decision Making, Sustainability, Hybrid Multi-Criteria Decision Making

Posted Date: March 19th, 2021

DOl: https://doi.org/10.21203/rs.3.rs-330269/v1

License: (c) (1) This work is licensed under a Creative Commons Attribution 4.0 International License. Read Full License

Version of Record: A version of this preprint was published at Soft Computing on November 13th, 2021. See the published version at https://doi.org/10.1007/s00500-021-06477-8. 


\title{
Green Supplier Selection in New Era for Sustainability: A Novel Method for Integrating Big Data Analytics and a Hybrid Fuzzy Multi-Criteria Decision Making
}

\author{
Abdullah YILDIZBASI*, Yagmur ARIOZ \\ Department of Industrial Engineering, Ankara Yıldırım Beyazıt University (AYBU), 06010, Ankara, TURKEY \\ ayildizbasi@ybu.edu.tr \\ Department of Industrial Engineering, Ankara Yıldırım Beyazıt University (AYBU), 06010, Ankara, TURKEY \\ ariozyagmur@gmail.com
}

\begin{abstract}
Environmentally conscious supplier selection has become increasingly important in recent years. Green supplier selection is one of the vital decisions of supply chain management, as it is preferred for businesses in the market that adopt an environmental approach and green philosophy in line with material and moral benefits. In this context, the problem of choosing the most efficient green supplier is addressed with a three-step methodology using big data analysis that includes an integrated approach and hybrid fuzzy AHP-TOPSIS techniques. First of all, big data plays an important role in delivering meaningful results by reducing complexity to a more fundamental level. It is possible to obtain more consistent results by examining a series of criteria in green supplier selection at a more reasonable and operational level. Thus, the role of big data analysis provides an input for decision-making, which enables a systematic reduction to more concise data. Then, these inputs are evaluated in a fuzzy environment with hybrid MCDM techniques and the most efficient green supplier is determined among the suppliers. This authentic study sheds light on providing a significant competitive advantage to businesses in line with their strategic targets as well as having environmental contributions to sustainability.
\end{abstract}

Keywords: Green Supplier Selection; Big Data; Fuzzy Decision Making; Sustainability; Hybrid MultiCriteria Decision Making

\footnotetext{
* Corresponding author.

E-mail address: ayildizbasi@ybu.edu.tr (Y1ldıbası A.)
} 


\section{Introduction}

The green supply chain has replaced the traditional supply chain management approach with the green approach and adoption of the green philosophy. The green supply chain is the process of incorporating environmental criteria or concerns into organizational purchasing decisions and long-term relationships with suppliers (İnce, 2013). Moreover, each one of these environmental criteria is a chain of data-based values that interact with each other. Additionally, the data-based approach can generate high profits for companies, and suppliers can set more assured strategic goals for their future based on the current situation through data analysis (Badiezadeh et al., 2018). Therefore, the importance of a data-based supply chain increases in the big data era (Li and Liu, 2019). Thus, businesses should not ignore the benefits of big data analytics, which is seen as expensive or a waste of time (Roßmann et al., 2018).

This article has addressed the green supplier selection, which is one of the strategic decisions of green supply chain management. Green supplier selection is an important and complex problem for businesses that need to consider the effects of multiple options including multiple choice and subjective judgments at the same time within the framework of the green philosophy (Yazdani, 2014). Big data plays an important role in getting meaningful results by reducing this complexity to a more fundamental level. In this context, green supplier selection has the data that is rapidly changing with high diversity and adds value to the performance of the green supply chain with its increasing feature.

$7 \mathrm{~V}$ dimensions of big data are characterized and analyzed in the conceptual framework in Figure 1.

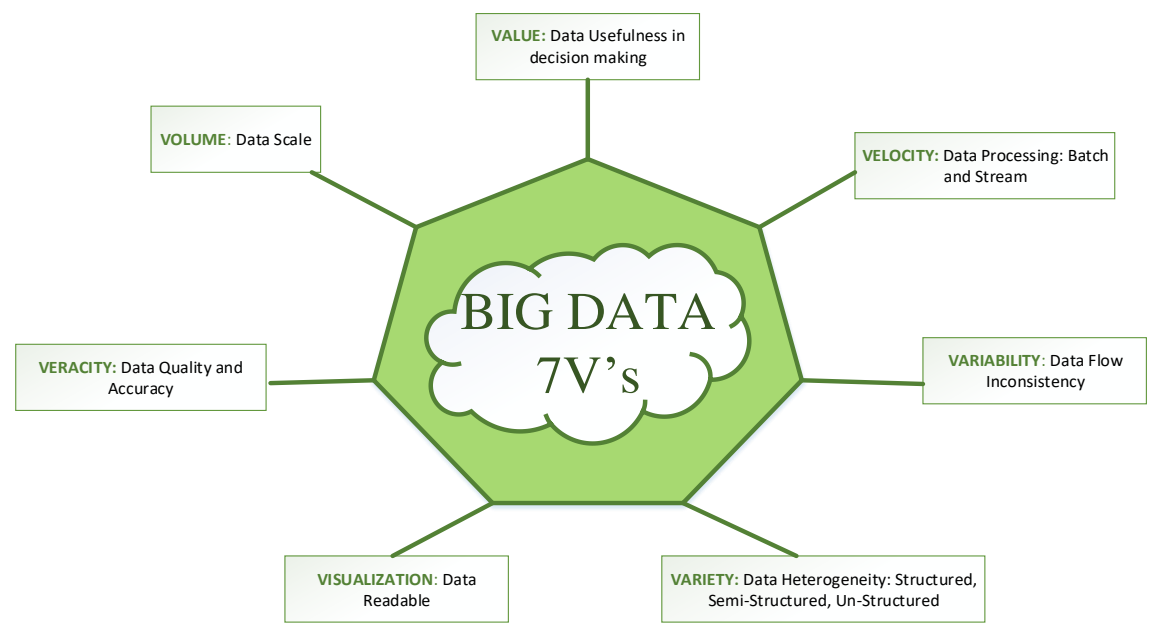

Figure 1. The 7V's characteristics of big data 
These dimensions have properties such as volume, velocity, variety, variability, veracity, visualization, and value. This conceptual framework aims to explain the multi-dimensional property of data in a more understandable way than one-dimension. It enables making data more meaningful by looking through a multi-dimensional perspective. In this regard, the 7Vs of big data are associated with the features of the green criteria used in green supplier selection, considering Table 1 and Figure 1.

Table 1. The seven V's characteristics of big data for the green supplier selection

\begin{tabular}{|c|l|}
\hline $\begin{array}{c}\text { DIMENSIONS } \\
\text { of BIG DATA } \\
(\mathbf{7 V})\end{array}$ & \multicolumn{1}{c|}{ GREEN CRITERIA } \\
\hline Volume & $\begin{array}{l}\text { Environmental problems, green policy, waste management, and all the procedures } \\
\text { required for an environmentally friendly production are becoming increasingly } \\
\text { important for suppliers, and thus environmental data is increasing. }\end{array}$ \\
\hline Velocity & $\begin{array}{l}\text { Suppliers provide an incredibly fast flow of data in the process of achieving their } \\
\text { vision of environmental sustainability. }\end{array}$ \\
\hline Variety & $\begin{array}{l}\text { Environmental factors such as green supply chain management, waste } \\
\text { management, and environmental management systems lead to diversity. }\end{array}$ \\
\hline Veracity & $\begin{array}{l}\text { It is a data feature that measures the consistency of the green policies and } \\
\text { procedures that the supplier follows. }\end{array}$ \\
\hline $\begin{array}{c}\text { Valence or } \\
\text { Visualization }\end{array}$ & $\begin{array}{l}\text { To visualize the processes of green supply chain management through charts, } \\
\text { graphics, and tables. }\end{array}$ \\
\hline Variability & $\begin{array}{l}\text { To measure suppliers' variability to situations such as environmental policies to } \\
\text { meet their needs to the expected extent. }\end{array}$ \\
\hline Value & $\begin{array}{l}\text { It determines how much value contributes to the sustainable supply chain after } \\
\text { examining the environmental dimension, along with the other six factors. }\end{array}$ \\
\hline
\end{tabular}

Big data analysis provides an input for decision-making, which enables a systematic reduction to more concise data. Considering that the green supplier selection is a multi-criteria problem, and there are many green criteria mentioned in the studies in the literature, the frequency density of these criteria was determined with big data analysis. The first ten criteria were selected, starting with the criteria with the highest frequency density. The suppliers were then listed by evaluating them in the fuzzy environment with hybrid multi-critera decision-making (MCDM) techniques. Thus, we aimed to demonstrate the accuracy of the results and the more reliable capability of strategic goals with integrated big data analysis with the fuzzy MCDM approach based on two basic methodologies.

Based on this motivation, this study aims to select the most efficient green supplier with fuzzy integrated MCDM approaches that take human judgments, doubts, and uncertainties into account according to the criteria determined by big data analysis. Accordingly, this study has addressed the following study questions: 
RQ1.Why is it important to select a green supplier in the supplier chain management?

RQ2.Why were integrated MCDM approaches used in the decision-making step of the green supplier selection?

RQ3.What kind of a role does big data analysis have on the problem of green supplier selection?

RQ4.What is the role of green suppliers on sustainability?

The remaining of this article was arranged as follows: In Section 2, the literature was reviewed by addressing the articles on green supplier selection within the scope of both content and methodology. In Section 3, the integrated fuzzy AHP-TOPSIS and big data analysis methodologies were addressed. In Section 4, a sample case study for a green supplier selection using the recommended methods was presented. In Section 5, the results were discussed. In Finally, Section 6, the conclusion, managerial implications, the future research scope, and the limitations of this study were explained.

\section{Literature Review}

There are many articles on big data applications in the supply chain in the literature. This literature includes theoretical and practical articles that are based on the multi-directional benefits of big data in the supply chain and its usage purposes. However, the number of articles that implement big data analysis in the problem of supplier selection is limited. The traditional problem of supplier selection has changed place with the green supplier selection with the increasing environmental sensitivity and awareness in the modern information and technology era. In this regard, we examined the literature review on the green supplier selection, which is a more specific subject, in terms of content and methodology in detail. The literature was reviewed with the keywords 'green supplier selection', 'big data analysis', 'supply chain mangement'.

Some articles in the literature addressed the problem of the green supplier selection as follows. Gupta et al. (2019) considered the positive effects of green supply chain management practices. They have assessed six suppliers under the umbrella of MCDM, which integrates three methodologies with "Multi-Attributive Border Approximation Area Comparison" (MABAC) noting that green supplier selection is based on traditional and mental criteria. The other three techniques are an integrated Fuzzy Analytic Hierarchy Process (FAHP), "Weighted Aggregated Sum-Product Assessment" WASPAS and "Technique for order preference by similarity to ideal Solution" (TOPSIS) within the MCDM framework. Together with these methodologies and 
sensitivity analysis, they aim at the most efficient supplier selection. Tang and Wei (2018) emphasized that due to environmental problems and ecological imbalance in China, businesses need to pay attention to the impact of their behavior on the environment in search of economic efficiency. Green supplier management has not been fully adopted in China compared to other countries. Several operators have been proposed with the generalized Pythagorean 2-double language in this context. Finally, an example of green supplier selection is implemented to prove the multi-featured decision-making process of the proposed algorithm.

Shen et al. (2013) noted the importance of green policy companies of environmental sustainability impact with increased environmental protection awareness, increased legislation, and regulations around the world. An example has been set for the problem of green supplier selection with TOPSIS in a fuzzy environment that takes into account people's subjective judgments and uncertainties. Lee et al. (2011) note which factors are more important in Taiwan's economy than the Taiwanese hand tool industry when choosing suppliers in a green supply chain. After a deep literature review, the criteria and important effect used in evaluating suppliers with the proposed fuzzy AHP approach were examined. Liu et al. (2019) described the green supplier problem as a significant Multi-Criterion Group Decision Making (MCGDM) problem that affects producer performance and efficiency. The validity and benefits of the proposed approach have been demonstrated by comparative analysis based on the MCGDM approach with the Hesitant Fuzzy Priority Weighted Average (HFPWA) operator. Lee et al. (2009) highlighted that green production has become a major problem for producers as suppliers worldwide awareness of environmental protection has increased. Delphi technique determined the criteria used to evaluate traditional and green suppliers. Suppliers were evaluated by applying the fuzzy AHP technique to obtain more consistent results by eliminating the ambiguities that arise from the opinions of experts, such as bias.

In this study, (Hashemi et al. (2015) proposed a comprehensive green supplier selection model problem using traditional criteria as well as economic and environmental criteria. With the Grey Relational Analysis (GRA) developed, green suppliers were evaluated by fuzzy ANP methods, which dealt with dependencies between criteria. Khalilzadeh and Derikvand (2018) have proposed a mathematical model taking into account green factors to the problem of technological change and supplier selection in the information age. The target of the model is total quality parts, taking into account the total greenhouse gas emissions, the suppliers have solved the uncertainty with stochastic programming through the multi-purpose linear program. As green supplier selection became more popular, Wu et al. (2019) developed data envelopment analysis (DEA) by converting this problem's ambiguous information with the Likert Scale into 
interval-valued Pythagorean fuzzy numbers (IVPFNs). Thus, they also support it with numerical sample and aim to make the most appropriate decision for the evaluation and selection of green suppliers.

Kannan et al. (2014) pointed out that the importance of green supply chain practices has increased with the increase in the effectiveness of green applications in daily activities. Evaluation of the TOPSIS method from twelve suppliers was conducted with three distinct graded methodologies. Statistical difference was determined using Spearman sequence correlation coefficient. In addition, the effect of decision makers on supplier selection was examined by sensitivity analysis. In this way, they aimed to provide awareness for suppliers by setting high importance criteria for green supplier selection. As examined in most articles, green supplier selection is a multi-criteria decision making problem. In general, MCDM techniques have been used with methodologies such as linear programming. Green supplier selection and integrated studies with the big data approach are deficiency in the literature. However, there is a very rare case of green supply chain management with big data analysis. One of these is the work of Zhao et al. (2017) proposed three objective optimization models within the context of the green philosophy in order to increase efficiency in the green supply chain. The data that will be entered into the optimization model are eliminated by statistical analysis and the appropriate ones are selected. Liu and Yi (2017) highlighted that green rating of products for the green supply chain in the big data environment in advertising is also a key factor in influencing sales. Four different game theories have been proposed. For green suppliers, this study guides targeted advertising and pricing policies in the big data environment.

Considering the categorization of the methodologies used in the green supplier selection, we noticed that big data analysis has formed a gap. The gap analysis regarding the methods used in the green supplier selection is presented in Table 2. We aimed to develop a different method that supports the problem of green supplier selection in relation to big data analysis based on this gap. According to the analysis presented in the table, MCDM techniques are more commonly used due to the essence of the problem of green supplier selection. Moreover, addressing it with hybrid methods in a fuzzy environment is used to give more consistent results in the problem of green supplier selection.

This article aims to select the most efficient green supplier with the MCDM methods, big data analysis, and fuzzy integrated MCDM approaches based on the relevant literature. This article recommended the fuzzy AHP-TOPSIS among the MCDM techniques and used a case study. The scope and usage priorities of methodologies were discussed in detail in Section 3. 
Table 2. GAP analysis on the methods used in green supplier selection

\begin{tabular}{|c|c|c|c|c|c|c|}
\hline \multirow{2}{*}{ AUTHORS } & \multicolumn{6}{|c|}{ USING METHODOLOGY } \\
\hline & Qualitative & $\begin{array}{l}\text { Mathematical } \\
\text { Programming }\end{array}$ & $\begin{array}{l}\text { MCDM \& } \\
\text { Mathematical } \\
\text { Analytic }\end{array}$ & Fuzzy & $\begin{array}{l}\text { Big } \\
\text { Data } \\
\text { Analysis }\end{array}$ & Other \\
\hline Lee et al. (2009) & $\checkmark$ & & $\checkmark$ & $\checkmark$ & & \\
\hline Wen \& Chi (2010) & & $\checkmark$ & & & & \\
\hline Kuo et al. (2010) & & & $\checkmark$ & & & \\
\hline Lee et al. (2011) & & & $\checkmark$ & $\checkmark$ & & \\
\hline Yeh \& Chuang (2011) & & & $\checkmark$ & $\checkmark$ & & \\
\hline $\begin{array}{c}\text { Büyüközkan \& Çifçi } \\
(2012)\end{array}$ & & & $\checkmark$ & & & \\
\hline Büyüközkan (2012) & & & $\checkmark$ & & & \\
\hline Shen et al. (2013) & & & $\checkmark$ & $\checkmark$ & & \\
\hline Kannan et al. (2013) & & & $\checkmark$ & $\checkmark$ & & \\
\hline Hashemi et al. (2014) & & & $\checkmark$ & & & \\
\hline Kannan et al. (2014) & & & $\checkmark$ & $\checkmark$ & & \\
\hline Zhao \& Guo (2014) & & & $\checkmark$ & $\checkmark$ & & \\
\hline Kannan et al. (2015) & & & $\checkmark$ & $\checkmark$ & & \\
\hline Hashemi et al. (2015) & & & & $\checkmark$ & & $\checkmark$ \\
\hline Rostamzadeh et al. (2015) & & & $\checkmark$ & $\checkmark$ & & \\
\hline Yu \& Hou (2016) & & & $\checkmark$ & & & \\
\hline $\begin{array}{c}\text { Govindan \& Sivakumar } \\
\text { (2016) }\end{array}$ & & & $\checkmark$ & $\checkmark$ & & \\
\hline Liu and Yi (2017) & & & & & & \\
\hline Zhao et al. (2017) & & $\checkmark$ & & & & \\
\hline Yazdani et al. (2017) & & & $\checkmark$ & & & \\
\hline Mousakhani et al. (2017) & & & $\checkmark$ & $\checkmark$ & & \\
\hline Khalilzadeh and & & & & & & \\
\hline Derikvand (2018) & & $\checkmark$ & & & & \\
\hline Tang and Wei (2018) & & & $\checkmark$ & & & \\
\hline Liu et al. (2019) & & & $\checkmark$ & $\checkmark$ & & \\
\hline Gupta et al. (2019) & & & $\checkmark$ & $\checkmark$ & & \\
\hline Wu et al. (2019) & & & $\checkmark$ & & & \\
\hline Rouyendegh et al. (2020) & & & $\checkmark$ & $\checkmark$ & & \\
\hline
\end{tabular}

\section{Methodology}

\subsection{Big Data Analysis}

Given the volume, speed, variety, and accuracy of big data analysis in the supply chain, the search for effective statistical methods that can be easily adapted have gained significant importance as traditional statistical methods have become obsolete (Wang et al. 2016). Big data analysis provides vital benefits to improve operational efficiency in the supply chain and help 
companies make better business decisions because of the ability to explore the potential market and provide information (Zhong et al. 2016). The problem of green supply selection represents a complex but important problem involving a range of data in this study. The criteria used in the selection of green suppliers were determined from the articles in the literature filtered according to the aforementioned keywords. These criteria play a useful role in obtaining meaningful results with self-criteria by reducing the complexity to a more fundamental level with big data analysis. The frequency density of each criterion used in green supplier selection was determined by big data analysis. These criteria provide input for the criteria to be used in MCDM methods.

\subsection{Multi-Criteria Decision Making Techniques(MCDM)}

Supplier selection is a multi-criteria, complex supply chain problem. Therefore, MCDM methods, which are frequently used in supplier selection, evaluate a set of alternatives based on more than one feature and then select the best alternative (Rashidi and Cullinane 2019). In this scope, This is why we aim to choose the best efficient green supplier with fuzzy integrated MCDM approaches that take into account human judgment, doubts, and uncertainties according to the criteria determined. In this context, we aimed to rank green suppliers by evaluating 10 criteria with the highest frequency density from big data analysis with the integrated MCDM techniques. After weighing the criteria with fuzzy AHP, one of the MCDM techniques, the alternatives were listed with the fuzzy TOPSIS method. The detailed steps of the methodologies are as follows:

\subsubsection{Fuzzy Set Theory}

For the first time in 1965, Zadeh emphasized that the concept of fuzzy logic stems from the misconceptions and uncertainties caused by human language, judgment, and assessments (Valmohammadi and Dashti 2016). His work has been a starting point with the publication of "Fuzzy Sets" in the "Information and Control" Magazine in the search for a solution to a technical problem. In fuzzy logic, 1 and 0 are seen as boundaries, not absolute values. The members in the fuzzy set receive values in this range. The membership function of a triangular fuzzy number is shown in Eq.(1) (Banaeian et al. 2018).

$$
\mu(\mathrm{x} / \mu)=\left\{\begin{aligned}
0, & x<1 \\
\frac{x-1}{m-1}, & 1 \leq x \leq m \\
\frac{r-x}{r-m}, & m \leq x \leq r \\
0, & x \geq r
\end{aligned}\right.
$$


Triangular fuzzy numbers are used as the membership function, which is illustrated in Figure 6:

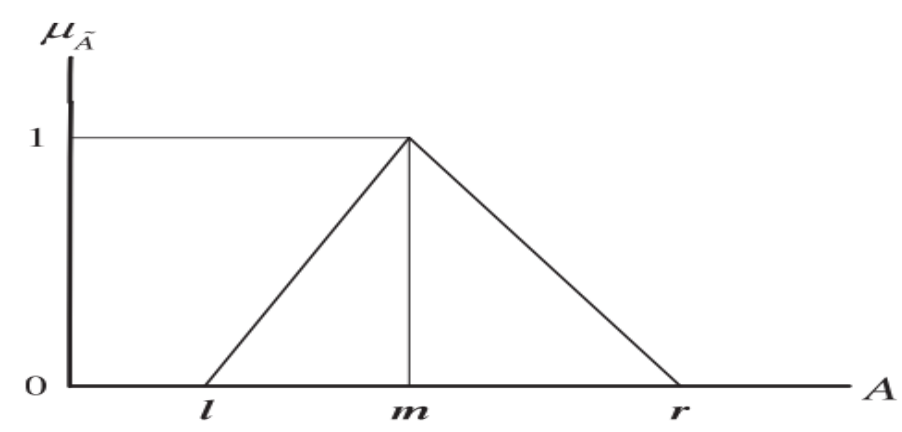

Figure 2. A membership function of the triangular fuzzy number

\subsubsection{Fuzzy AHP Method}

The analytical hierarchy process (AHP) method, first proposed by Saaty (1980), is one of the multi-criteria decision-making methods. This method is used that can choose from a large number of alternatives and where more than one decision-maker can take part situated in the process. Moreover, this method can be easily applied even in very complex problems due to the fact that it takes into account both quantitative and qualitative factors and is simple and useful. (Göksu \& Güngör, 2008).Fuzzy AHP method steps defined as follows (Torfi, Farahani, and Rezapour 2010).

Step1. Fuzzy triangular numbers indicate the importance levels of the criteria relative to each other by expert decision-makers. Very Low (VL), Low (L), Medium (M), high (H), Very High (VG) scale in Table 3 has been used to express with five-dimensional linguistic ratios (Awasthi et al. 2018). The purpose of the comparison matrix in comparing the elements of the generated hierarchy into pairs is to determine their relative precedence over each of the elements at the next higher level. A decision matrix consisting of a fuzzy set is created. 
Table 3. Linguistic rating and fuzzy number

\begin{tabular}{|c|c|}
\hline Linguistic Term (Criteria) & Fuzzy Triangular Number \\
\hline Very Low (VL) & $(1,1,3)$ \\
\hline Low (L) & $(1,3,5)$ \\
\hline Medium (M) & $(3,5,7)$ \\
\hline High $(\mathrm{H})$ & $(5,7,9)$ \\
\hline Very High (VG) & $(7,9,9)$ \\
\hline 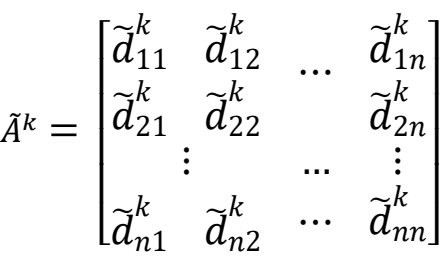 & \\
\hline
\end{tabular}

Step 2. By finding the geometric mean for each column in the binary comparison matrix, it is divided into all the elements in the corresponding column, and a normalized binary comparison matrix $(\mathrm{R})$ is created.

$\mathrm{R}=\left[\begin{array}{ccc}\tilde{d}_{11} & \cdots & \tilde{d}_{1 n} \\ \vdots & \ddots & \vdots \\ \tilde{d}_{n 1} & \cdots & \tilde{d}_{n n}\end{array}\right]$

$\tilde{\boldsymbol{r}}_{i}=\left(\prod_{j=1}^{n} \widetilde{\boldsymbol{d}}_{i j}\right)^{1 / n}, i=1,2, \ldots, \mathrm{n}$

Step 3. The criterion weights vector (w) is calculated by taking the arithmetic mean of all the elements in each row of the normalized binary comparison matrix.

$\widetilde{w}_{i}=\tilde{\boldsymbol{r}}_{\boldsymbol{i}} \otimes\left(\tilde{\boldsymbol{r}}_{1} \oplus \tilde{\boldsymbol{r}}_{2} \oplus \tilde{\boldsymbol{r}}_{3} \oplus \ldots \ldots \oplus \tilde{\boldsymbol{r}}_{\boldsymbol{n}}\right)^{-1}$

$=($ lwi, mwi, uwi )

Step 4. Rinsing operations are applied to the fuzzy weight values for each criterion.

$M_{i}=\frac{l w_{i}+m w_{i}+u w_{i}}{3}$

Step 5. The step ends by normalizing the rinsed values. 
$N_{\dot{\mathrm{I}}}=\frac{M_{i}}{\sum_{i=1}^{n} M_{i}}$

\subsubsection{Fuzzy TOPSIS Method}

Developed by Yoon and Hwang, the TOPSIS Method is to choose the alternative that has the closest distance to the positive ideal solution and the closest distance to the negative ideal solution (Ara 2015). The fuzzy TOPSIS method which aims to solve multi-criteria decisionmaking problems under a fuzzy environment and to eliminate ambiguities in decision-makers of evaluations and to keep biases to a minimum is more convenient than the traditional TOPSIS method (Sirisawat and Kiatcharoenpol 2018). In this respect, this MCDM technique is frequently used in supplier selection problems. Fuzzy TOPSIS method steps defined as follows (Torfi et al. 2010; Banaeian et al. 2018). The linguistic variable scale in Table 4 was used to rate the criteria (Banaeian et al. 2018).

Table 4. Linguistic variables for green supplier ratings

\begin{tabular}{lc}
\hline Linguistic Term(Criteria) & Fuzzy Triangular Number \\
\hline Very Poor (VP) & $(0,1,2)$, \\
Poor (P) & $(1,2,3)$ \\
Medium Poor (MP) & $(2,3.5,5)$ \\
Fair (F) & $(4,5,6)$ \\
Medium Good (MG) & $(5,6.5,8)$ \\
Good (G) & $(7,8,9)$ \\
Very Good (VG) & $(8,9,10)$ \\
\hline
\end{tabular}

Step 1. Construct the fuzzy decision-making matrice. MCDM problem includes a group of $\mathrm{k}$ decision-makers $(\mathrm{D} 1, \mathrm{D} 2, \ldots, \mathrm{Dk})$ containing $\mathrm{m}$ alternatives $(\mathrm{A} 1, \mathrm{~A} 2, \ldots, \mathrm{Am})$ and $\mathrm{n}$ criteria $(\mathrm{C} 1, \mathrm{C} 2, \ldots, \mathrm{Cn})$. In a group of $\mathrm{k}$ decision-makers, the criterion values of the alternatives are calculated as follows

$\tilde{x}_{i j}=\frac{1}{K}\left[\tilde{x}_{i j}^{1}+\tilde{x}_{i j}^{2}+\cdots \tilde{x}_{i j}^{K}\right]$

Step 2. $\tilde{x}_{i j}(\forall i, j)$ ve $\widetilde{w}_{j},(j=1,2, . ., n)$ are linguistic triangular fuzzy numbers $A_{1}, A_{2}, \ldots, A_{m}$ alternatives; $K_{1}, K_{2}, \ldots, K_{n}$ decision criteria. $\tilde{x}_{i j}=K_{j}$ shows that the fuzzy criterion value of the $A_{i}$ alternative relative to the $K_{j}$ criterion and the fuzzy significance weight of the $\widetilde{w}_{j}=K_{j}$ criterion. 
These linguistic variables can be expressed with triangular fuzzy numbers $\tilde{x}_{i j}=\left(a_{i j}, b_{i j}, c_{i j}\right)$ and $\widetilde{w}_{j}=\left(a_{j 1}, b_{j 2}, c_{j 3}\right)$. The matrix $\mathrm{D}$ is called the fuzzy decision matrix and the matrix $\mathrm{W}$ is called the fuzzy weights matrix.

$$
\begin{aligned}
& \begin{array}{llll}
K_{1} & K_{2} & \ldots & K_{n}
\end{array}
\end{aligned}
$$

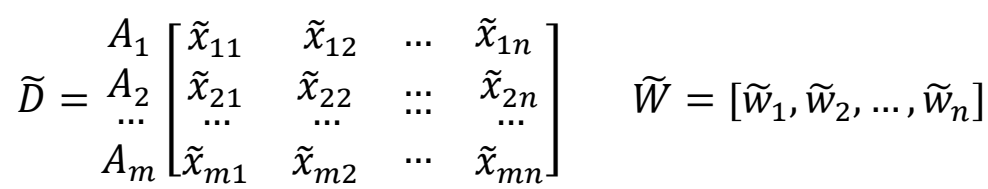

Step 3. Normalized fuzzy decision matrix obtained from fuzzy decision matrix.

$$
\begin{aligned}
& \tilde{R}=\left[\tilde{r}_{i j}\right]_{m x n} \\
& \tilde{r}_{i j}=\left(\frac{a_{i j}}{c_{j}^{*}}, \frac{b_{i j}}{c_{j}^{*}}, \frac{c_{i j}}{c_{j}^{*}}\right), j \in B, c_{j}^{*}=\max _{i} c_{i j}, \\
& \tilde{r}_{i j}=\left(\frac{a_{j}^{-}}{c_{i j}}, \frac{a_{j}^{-}}{b_{i j}}, \frac{a_{j}^{-}}{a_{i j}}\right), j \in B, a_{j}^{-}=\min _{i} a_{i j},
\end{aligned}
$$

Step 4. Fuzzy decision matrix normalized to weight of criteria

$\tilde{V}=\left[\widetilde{V}_{i j}\right]_{m x n}$

$$
\tilde{V}_{i j}=\tilde{r}_{i j} \times \widetilde{w}_{j}
$$

Step 5. Calculation of fuzzy positive ideal solution and fuzzy negative ideal solution of criteria.

$$
\begin{array}{ll}
A^{*}=\left(\tilde{V}_{1}^{*}, \tilde{V}_{2}^{*}, \ldots, \tilde{V}_{n}^{*}\right) & \text { pozitif ideal solution } \\
A^{-}=\left(\tilde{V}_{1}^{-}, \tilde{V}_{2}^{-}, \ldots, \tilde{V}_{n}^{-}\right) & \text {negative ideal solution }
\end{array}
$$

The distances of fuzzy positive and negative ideal solutions for alternatives are calculated as follows:

$$
\begin{array}{ll}
d_{i}^{*}=\sum_{j=1}^{n} d\left(\tilde{v}_{i j}, \tilde{v}_{j}^{*}\right), & i=1,2, \ldots, m \\
d_{i}^{-}=\sum_{j=1}^{n} d\left(\tilde{v}_{i j}, \tilde{v}_{j}^{-}\right), & i=1,2, \ldots, m
\end{array}
$$

Calculation of distance between two triangular fuzzy numbers sayı $\tilde{a}=\left(a_{1}, a_{2}, a_{3}\right)$ and $\tilde{b}=$ $\left(b_{1}, b_{2}, b_{3}\right)$ using Vertex method, 


$$
d(\tilde{a}, \tilde{b})=\sqrt{\frac{1}{3}\left[\left(a_{1}-b_{1}\right)^{2}+\left(a_{2}-b_{2}\right)^{2}+\left(a_{3}-b_{3}\right)^{2}\right]}
$$

Step 6. Calculate the similarities to ideal solution.

$$
C C_{i}=\frac{d_{i}^{-}}{d_{i}^{*}+d_{i}^{-}}, \quad i=1,2, \ldots, m
$$

Step 7. Rank preference order. Choose an alternative with maximum $C C_{i}$ or rank alternatives according to $C C_{i}$ in descending order.

\section{Case Study}

In this study, four different electronics industry suppliers were evaluated by three expert decision-makers to the problem of choosing the most efficient green supplier. The case study consists of two main parts. The first decision is to determine the criteria to be used in the selection of green suppliers by big data analysis. The second part covers the application of methodologies for multi-criteria decision-making methods used to evaluate suppliers. Green suppliers were evaluated using integrated AHP-TOPSIS methodologies in the fuzzy environment from MCDM methods.

\subsection{Big Data Analysis}

In this part, dataset consisting all of the articles from different sources are used to calculate the frequency keywords and keyword groups (bigrams and trigrams) automatically. This dataset refers to criteria related to green supplier selection articles. The big data analysis is derived from a textual analysis of the articles in the literature. In this regard, a total of 79 criteria used for the selection of green suppliers are identified. Evaluating all criteria for suppliers makes the problem more difficult and complex.

In this scope, it is important to know the frequency of these ngrams to classify and represent the articles and also the domain. Premade ngram list is provided by the authors of the chapter. The criter name and the representation of the total number of scanned articles are as follows: ("['criter name']",count)

Here you can see the ngram list:

("['cost']", 2576),

("['quality']", 1922),

("['flexibility']", 248),

("['environmental', 'management', 'system']", 61), 
("['speed']", 39),

("['green', 'production']", 29),

("['green', 'technology']", 21),

("['after', 'sales', 'service']", 18),

("['innovativeness']", 17),

("['delivery', 'reliability']", 17),

("['green', 'logistics']", 14),

("['on', 'time', 'delivery']", 14),

("['cleaner', 'technology']", 13),

("['biodiversity']", 12),

("['performance', 'history']", 11),

("['dependability']", 11),

("['reduce', 'reuse', 'recycling']", 10)]

("['donations']", 10),

("['global', 'risks']", 10),

("['direct', 'cost']", 9),

("['labour', 'practices']", 7),

("['design', 'for', 'environment']", 7),

("['greenhouse', 'gas', 'emission']", 6),

("['defect', 'ratio']", 6),

("['job', 'opportunities']", 6),

("['financial', 'capability']", 5),

("['decent', 'work']", 5),

("['local', 'communities']", 5),

("['economic', 'growth']", 5),

("['resource', 'allocation']", 5),

("['green', 'development']", 4),

("['energy', 'conservation']", 4),

("['materials', 'energy']", 4),

("['green', 'packing']", 4),

("['reuse', 'recycling']", 4),

("['quality', 'of', 'relationship']", 4),

("['supplier', 'social', 'selection']", 4),

("['labour', 'health']", 4),

("['social', 'commitment']", 4),

("['environmental', 'selection', 'procedure']", 3),

("['legal', 'compliance']", 3),

("['staff', 'development']", 3),

("['ethical', 'issues']", 2),

("['worker', 'dismissal']", 2),

("['currency', 'risk']", 2),

("['effectiveness', 'of', 'communication']", 1),

("['safety', 'system']", 1),

("['job', 'safety']", 1),

("['desire', 'for', 'business']", 1),

("['products', 'quality', 'improvement']", 1),

("['indirect', 'cost']", 1),

("['safety', 'audit', 'assessment']",1),

("['product', 'responsibility']", 1),

("['buyer', 'supplier', 'constraints']", 1),

("['economic', 'welfare']", 1),

("['e-commerce', 'capability']", 1),

("['vocational', 'health']", 1),

("['information', 'revelation']", 1),

("['worker', 'safety']", 1), 
("['economical', 'welfare']", 1),

("['local', 'communication', 'influence']", 1),

("['stakeholder', 'engagement']", 1),

("['tax', 'payment']", 1),

("['currency', 'risks']", 1),

("['cultural', 'compatibility']", 1),

("['business', 'criterias']", 1)

("['cost', 'reduction', 'activities']", 1),

("['supply', 'flexibility']", 1),

("['revenue', 'on', 'product']", 1),

("['technonolgy', 'capability']", 1),

("['service', 'capanbility']", 1)]

("['water', 'recycling']", 1),

("['effluents', 'and', 'waste']", 1),

("['resource', 'conservation']", 1),

("['trash', 'management']", 1),

("['green', 'labeling']", 1),

("['environmental', 'management', 'certifications']", 1),

("['reduce', 'reuse', 'recycling']", 1),

("['energy', 'resource', 'consumption']", 1)

The system is implemented in python programming language andThe Pseudo code is as follows:

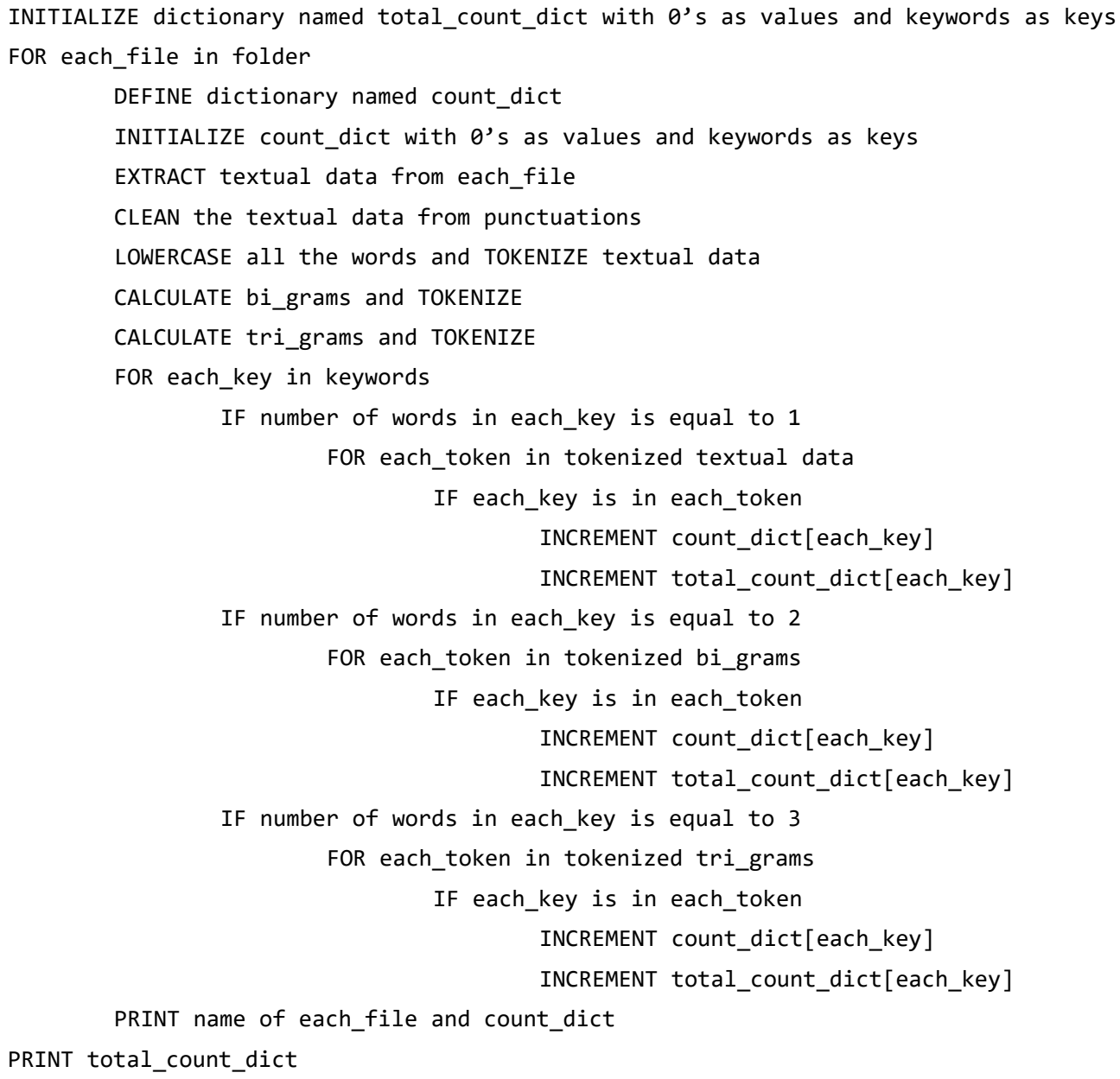


The code is implemented to be used as a simple console program. Basically it uses the provided ngram list as input to search through a folder consisting articles. To be able to correctly search through the article there should be some pre-processing to be done prior. This includes making everything lowercase (including ngrams which is also provided to the system as a simple text file), remove punctuations and removing new lines. Lastly, bigrams and trigrams are created as well as unigrams. After that the same tokenization steps are also applied to the keyword file as well to maintain homogenious data type. At the end we have a list of tokenized $\mathrm{n}$ grams for wanted keywords and also tokenized ngrams of the data to be searched through. When the code is executed it produces detailed report of the frequency of ngrams from keyword file for each article and also for all files in total.

According to the results, the 10 criteria with the highest frequency density are shown in Table 5.

Table 5. Results of the total count of each criterion

\begin{tabular}{lc}
\hline \multicolumn{1}{c}{ CRITERIA } & COUNT \\
\hline Cost (C1) & 2576 \\
Quality (C2) & 1922 \\
Speed (C3) & 39 \\
Flexibility (C4) & 248 \\
After-sales service (C5) & 18 \\
Green Production (C6) & 29 \\
Green Technology (C7) & 21 \\
Green Logistics (C8) & 14 \\
Reduce, Reuse, Recycling(3R) (C9) & 10 \\
Environmental Management System (C10) & 61 \\
\hline
\end{tabular}

\subsection{Multi-Criteria Decision Making Applications}

In the second part of the case analysis, the criteria determined by big data analysis were evaluated using MCDM techniques.

\subsubsection{Application of Fuzzy AHP}

Step 1. For each criterion, a decision matrix determined by linguistic variables is generated as in Table 6. 
Table 6. Linguistics ratings of criteria for decision matrix

\begin{tabular}{|c|c|c|c|c|c|c|c|c|c|c|}
\hline CRITERIA & $\begin{array}{l}\text { Cost } \\
\text { (C1) }\end{array}$ & Quality(C2) & Speed(C3) & Flexibility(C4) & \begin{tabular}{|l}
$\begin{array}{l}\text { After sales } \\
\text { service(C5) }\end{array}$ \\
\end{tabular} & $\begin{array}{c}\text { Green } \\
\text { Production } \\
\text { (C6) }\end{array}$ & $\begin{array}{c}\text { Green } \\
\text { Technology(C7) }\end{array}$ & $\begin{array}{c}\text { Green } \\
\text { Logistics(C8) } \\
\end{array}$ & $\begin{array}{c}\text { Reduce,Reuse, } \\
\text { Recycling(3R) } \\
\text { (C9) }\end{array}$ & $\begin{array}{c}\text { Environmental } \\
\text { Managemet } \\
\text { System (C10) } \\
\end{array}$ \\
\hline Cost (C1) & $(1,1,1)$ & $(1,3,5)$ & $(3,5,7)$ & $(5,7,9)$ & $(3,5,7)$ & $(5,7,9)$ & $(5,7,9)$ & $(5,7,9)$ & $(3,5,7)$ & $(3,5,7)$ \\
\hline$\overline{\text { Quality(C2) }}$ & & $(1,1,1)$ & $(3,5,7)$ & $(5,7,9)$ & $(5,7,9)$ & $(3,5,7)$ & $(3,5,7)$ & $(3,5,7)$ & $(1,3,5)$ & $(1,3,5)$ \\
\hline 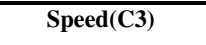 & & & $(1,1,1)$ & $(1,3,5)$ & $(1,3,5)$ & $(1,1,3)$ & $(1,1,3)$ & $(1,1,3)$ & $(1,1,3)$ & $(1,1,3)$ \\
\hline Flexibility(C4) & & & & $(1,1,1)$ & $(1,3,5)$ & $(1,1,3)$ & $(1,1,3)$ & $(1,1,3)$ & $(1,3,5)$ & $(1,3,5)$ \\
\hline $\begin{array}{l}\text { After-sales service } \\
\text { (C5) }\end{array}$ & & & & & $(1,1,1)$ & $(1,1,3)$ & $(1,3,5)$ & $(1,3,5)$ & $(1,1,3)$ & $(1,1,3)$ \\
\hline $\begin{array}{c}\text { Green } \\
\text { Production(C6) }\end{array}$ & & & & & & $(1,1,1)$ & $(5,7,9)$ & $(1,3,5)$ & $(1,1,3)$ & $(1,1,3)$ \\
\hline $\begin{array}{c}\text { Green } \\
\text { Technology(C7) }\end{array}$ & & & & & & & $(1,1,1)$ & $(1,3,5)$ & $(1,1,3)$ & $(1,1,3)$ \\
\hline $\begin{array}{c}\text { Green } \\
\text { Logistics(C8) }\end{array}$ & & & & & & & & $(1,1,1)$ & $(1,1,3)$ & $(1,1,3)$ \\
\hline $\begin{array}{l}\text { Reduce, Reuse, } \\
\text { Recycling(3R)(C9) }\end{array}$ & & & & & & & & & $(1,1,1)$ & $(1,1,3)$ \\
\hline $\begin{array}{c}\text { Environmental } \\
\text { Management } \\
\text { System(C10) }\end{array}$ & & & & & & & & & & $(1,1,1)$ \\
\hline
\end{tabular}

Step 2. The geometric mean values of the values in the normalized decision matrix are shown in Table 7.

Table 7. The geometric mean of fuzzy comparison values of criteria (ri)

\begin{tabular}{llll}
\hline & \multicolumn{3}{c}{ ri } \\
\hline C1 & 2,7864 & 4,4194 & 5,9066 \\
C2 & 1,3160 & 1,8481 & 2,8173 \\
C3 & 0,2732 & 0,3419 & 0,4807 \\
C4 & 0,2229 & 0,2871 & 0,4472 \\
C5 & 0,2293 & 0,3164 & 0,5818 \\
C6 & 0,2894 & 0,5529 & 0,6367 \\
C7 & 0,1843 & 0,3328 & 0,4869 \\
C8 & 0,2552 & 0,4396 & 0,6791 \\
C9 & 0,3027 & 0,6213 & 0,8716 \\
C10 & 0,3059 & 0,6551 & 0,8850 \\
\hline
\end{tabular}

Step 3. The importance weights of each criterion were calculated according to equation 4 and is shown in table 8 .

Table 8. The importance weight of the criteria

\begin{tabular}{llll}
\hline & \multicolumn{3}{c}{ Wi } \\
\hline C1 & 0,2020 & 0,4502 & 0,9579 \\
C2 & 0,0954 & 0,1882 & 0,4569 \\
C3 & 0,0198 & 0,0348 & 0,0779 \\
C4 & 0,0161 & 0,0292 & 0,0725 \\
C5 & 0,0166 & 0,0322 & 0,0943 \\
C6 & 0,0209 & 0,0563 & 0,1032 \\
C7 & 0,0133 & 0,0339 & 0,0789 \\
C8 & 0,0185 & 0,0447 & 0,1101
\end{tabular}




\begin{tabular}{cccc} 
C9 & 0,0219 & 0,0633 & 0,1413 \\
C10 & 0,0221 & 0,0667 & 0,1435 \\
\hline
\end{tabular}

The criterion weights found with the Fuzzy AHP method were used in the Fuzzy TOPSIS method.

\subsubsection{Application of Fuzzy TOPSIS}

Step 1. Created of fuzzy decision matrix with linguistic variables and is shown in table 9.

Table 9. Linguistic evaluation data of alternatives

\begin{tabular}{|c|c|c|c|c|c|c|c|c|c|c|c|}
\hline & & $\operatorname{Cost}(\mathrm{C1})$ & Quality(C2) & Speed(C3) & Flexibility(C4) & $\begin{array}{c}\text { After } \\
\text { sales } \\
\text { service } \\
(\text { C5) }\end{array}$ & $\begin{array}{c}\text { Green } \\
\text { Production(C6) }\end{array}$ & $\begin{array}{c}\text { Green } \\
\text { Technology(C7) }\end{array}$ & $\begin{array}{c}\text { Green } \\
\text { Logistics(C8) }\end{array}$ & $\begin{array}{c}\text { Reduce,Reuse, } \\
\text { Recycling(3R)(C9) }\end{array}$ & $\begin{array}{c}\text { Environmental } \\
\text { Management } \\
\text { System(C10) }\end{array}$ \\
\hline \multirow{4}{*}{ DM1 } & S1 & G & MG & $\mathrm{P}$ & F & F & MP & $\mathrm{P}$ & F & MP & F \\
\hline & S2 & MG & MG & G & MG & $\mathrm{F}$ & MG & F & MG & G & G \\
\hline & S3 & $\mathrm{P}$ & F & $\mathrm{P}$ & MP & G & MP & $\mathrm{F}$ & MP & $\mathrm{P}$ & MP \\
\hline & S4 & MP & MG & MP & MP & G & F & MP & $\mathrm{P}$ & MG & MG \\
\hline \multirow{4}{*}{ DM2 } & S1 & MG & MG & G & MG & G & MG & $\mathrm{F}$ & $\mathrm{F}$ & MG & MG \\
\hline & S2 & $\mathrm{F}$ & MP & $\mathrm{F}$ & $\mathrm{VP}$ & $\mathrm{P}$ & MP & MP & MP & $\mathrm{F}$ & MP \\
\hline & S3 & VG & VG & G & MG & VG & G & MG & G & G & G \\
\hline & S4 & MG & F & G & MG & F & G & MG & F & G & MG \\
\hline \multirow{4}{*}{ DM3 } & S1 & VG & MG & MP & $\mathrm{F}$ & G & MG & MP & MG & G & MG \\
\hline & S2 & MP & MG & MP & VP & G & MP & F & VP & MG & $\mathrm{P}$ \\
\hline & $\mathbf{S 3}$ & VG & MG & G & MG & MG & G & MG & $\mathrm{F}$ & VG & G \\
\hline & S4 & MG & MP & MG & G & MP & MG & G & MP & MG & G \\
\hline
\end{tabular}

Step 2. After filling in the numerical values corresponding to the linguistic variables, the min, and max ideal values for each criterion are shown in Table 10.

Table 10. Pozitif and negative ideal solution values

\begin{tabular}{llllllll}
\hline \multicolumn{3}{c}{ Max Value A+ } & \multicolumn{5}{c}{ Min Value A- } \\
\hline C1 & 0,0890 & 0,2331 & 0,5698 & C1 & 0,0489 & 0,1488 & 0,4010 \\
C2 & 0,0366 & 0,0873 & 0,2480 & C2 & 0,0237 & 0,0638 & 0,1964 \\
C3 & 0,0073 & 0,0156 & 0,0426 & C3 & 0,0049 & 0,0117 & 0,0329 \\
C4 & 0,0059 & 0,0137 & 0,0416 & C4 & 0,0021 & 0,0064 & 0,0227 \\
C5 & 0,0073 & 0,0168 & 0,0565 & C5 & 0,0044 & 0,0107 & 0,0377 \\
C6 & 0,0078 & 0,0257 & 0,0556 & C6 & 0,0044 & 0,0178 & 0,0435 \\
C7 & 0,0056 & 0,0178 & 0,0494 & C7 & 0,0023 & 0,0089 & 0,0276 \\
\hline
\end{tabular}




\begin{tabular}{cccccccc}
\hline C8 & 0,0065 & 0,0200 & 0,0598 & C8 & 0,0035 & 0,0127 & 0,0418 \\
C9 & 0,0089 & 0,0305 & 0,0788 & C9 & 0,0065 & 0,0244 & 0,0667 \\
C10 & 0,0085 & 0,0319 & 0,0817 & C10 & 0,0050 & 0,0205 & 0,0555 \\
\hline
\end{tabular}

Step 3. The distance of each alternative from the positive ideal solution and the negative ideal solution was calculated and is shown in table 11.

Table 11. A positive ideal solution and the negative ideal distance according to alternatives

\begin{tabular}{lcc}
\hline & $\mathrm{d}+$ & $\mathrm{d}-$ \\
\hline S1 & 0,0274 & 0,1082 \\
S2 & 0,1272 & 0,0182 \\
S3 & 0,0615 & 0,0940 \\
S4 & 0,1015 & 0,0539 \\
\hline
\end{tabular}

Step 4. The coefficient index was calculated for each alternative and presented in Table 12.

Table 12. Coefficient index according to alternatives

\begin{tabular}{lr}
\hline & C* \\
\hline S1 & 0,7976 \\
S2 & 0,1252 \\
S3 & 0,6044 \\
S4 & 0,3468 \\
\hline
\end{tabular}

Step 5. Ranking the alternatives

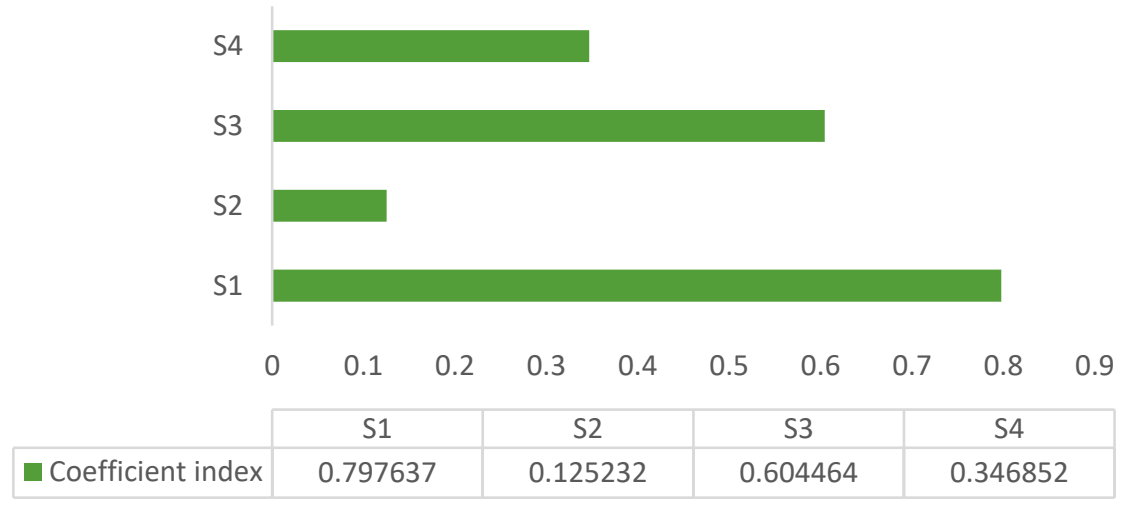

Figure 3. Ranking Results 


\section{Result and Discussion}

In this study, four different electronics industry suppliers were evaluated according to the green criteria. The green criteria to be used in supplier selection were determined with big data analysis among many criteria. According to the results obtained with the fuzzy TOPSIS method using the weights obtained from the fuzzy AHP method, Supplier1 and Supplier3 have higher values of 0.797637 and 0.604464 , respectively. On the other hand, Supplier2 and Supplier4 are by far lower with coefficient index values of 0.125232 and 0.346852 , respectively.According to the results obtained in Figure 7, it is seen that green suppliers are listed as $\mathrm{S} 1>\mathrm{S} 3>\mathrm{S} 4>\mathrm{S} 2$ in the environmental dimension of sustainability. This situation can be turned into opportunities that create a competitive advantage for suppliers.

It can be said that Supplier1 and Supplier3 adopt green production, technology, and logistics activities since they are more efficient green suppliers. Additionally, it can be said that these suppliers act in accordance with environmental management systems and implement 3R (Reduce, Reuse, Recycle) circular economy strategies for their businesses. Since these suppliers are more environmentally friendly, sensitive, and conscious, they can be preferred more than other suppliers in the competitive market. Thus, they can also bring high profits to their businesses besides contributing to environmental sustainability.

Supplier2 and Supplier4 need to develop their strategies from an environmental point of view to take part in the competitive market. They should adopt and implement the environmental management system as a corporate culture in their businesses. They need to address the green approach in all activities of the supply chain from production to logistics. Moreover, recyclingoriented activities contribute to their businesses both environmentally and economically. Therefore, Supplier2 and Supplier4 should not ignore these contributions to the future of their business.

Green suppliers also provide indispensable value for the environmental dimension, which is an indispensable condition for sustainability. In this regard, environmentally conscious green suppliers, which are becoming more important every day, will be the reason to be preferred more than other suppliers. 


\section{Conclusion}

Environmentally conscious supplier selection has become increasingly important in recent years. Thus, this article contains an integrated approach to achieve the goal of the most efficient green supplier selection problem. This study also uses a fuzzy approach within the proposed three-step methodology. The use of fuzzy MCDM techniques with big data analysis addresses the green supplier selection problem from a different perspective beyond the traditional understanding. The proposed methodology has been applied to the problem of selecting the most efficient green supplier on four different electronics industry suppliers, including three expert decision-makers. First of all, it is possible to obtain more consistent results with big data analysis by examining the green supplier selection, which is a problem related to a series of criteria, complex and strategic decisions, at a more reasonable and operational level. The ten most frequently used (frequency density) criteria in the selection of green suppliers among the articles scanned with big data analysis were determined by big data analysis. The weight of each criterion was determined using fuzzy AHP. Benchmark weights were then compared by three supply experts using the fuzzy TOPSIS method. The results are more accurate within the framework of fuzzy logic, which takes human doubts, judgments, and uncertainties into account. In addition, the ranking of suppliers is also related to the $7 \mathrm{~V}$ dimensions of big data that raises awareness to provide a competitive advantage to suppliers. The dimensional approach enables having a better understanding of green criteria compared to the conceptual framework. The fact that the green supplier selection problem was addressed both with big data analysis and hybrid fuzzy MCDM methods shows that this is an authentic study that contributes to the literature. The problem of green supplier selection contributes to sustainability as well as providing a significant competitive advantage to businesses in line with their strategic goals.

\subsection{Managerial Implications}

This study focused on the effects of the green supplier selection problem on the performance of chain stakeholders of suppliers in the electronics industry. Thus, the results obtained from the study can be a guide for both supply chain practitioners and academics. This study determined the green criteria with big data analysis and evaluated four suppliers based on these criteria. The efforts of companies to select green suppliers and their investments in this direction can be effective in increasing their competitiveness.

Therefore, we consider the following implications to be important in managerial approaches: 
* Since the top management is responsible for the development and planning of environmental policies, the results of this study can be evaluated by senior executives.

* Thanks to the approach we propose in this article, companies can seize significant improvement opportunities in terms of environmental sustainability.

* The suppliers, who have adopted the green philosophy and consider environmental sustainability, can be determined with the proposed approach in the selection process of the suppliers.

* Fuzzy AHP and TOPSIS hybrid methodology can be used to monitor companies' environmental sustainability performance and make comparisons in this direction.

* Green criteria may differ between sectors. Therefore, the criteria obtained from big data analysis can be considered in a broader or narrower framework.

* The results of the approach focused in this study were obtained in line with the opinions of decision-makers. So, each company can manage its own evaluation and decision-making process with its own evaluation process (Yıldızbaşı et al., 2020).

* It is necessary to consider environmental sustainability to gain a competitive advantage in the modern world market where environmentally conscious businesses are preferred. Senior executives can take their place in the leading position in the market by developing strategies in this context.

\subsection{Limitations and Future Scope}

Although this was a comprehensive study, it also had limitations that need to be guiding for future studies. One of the main limitations of this study is that it only focused on fuzzy AHP and fuzzy TOPSIS methods. It might be useful to evaluate green suppliers with other methods in addition to these methods (Memari et al., 2019). Additionally, this study focused on the electronics industry. There might be different green criteria that affect the environmental dimension of the sustainability of each industry. In this regard, green suppliers can be evaluated in different industries.

Additionally, this article is suitable for implementations in various supplier selection problems. It can be applied in the evaluation of multiple suppliers in problems that contain multidimensional, complex, and comprehensive data set such as the problem of sustainable supplier selection. According to the results obtained, the relationships between all dimensions of 
sustainability can be discussed. Additionally, this study weighted decision-makers personally. Future studies can weight decision-makers based on their experiences and knowledge (Yıldızbaşı et al., 2020).

\section{Declarations}

Funding: The author(s) received no financial support for the research, authorship, and/or publication of this article.

Conflicts of Interest: The authors declare no conflict of interest.

Availability of data and material: The datasets generated during and/or analyzed during the current study are available from the corresponding author on reasonable request.

Code availability: The code generated during and/or analyzed during the current study are available from the corresponding author on reasonable request.

Ethical Approval: Neither the article nor portions of it have been previously published elsewhere. The manuscript has not been submitted to more than one journal for simultaneous consideration.

Consent to Participate: This article does not contain any studies with human participants or animals performed by any of the authors.

Consent to Publish: All authors consent to the publication of the manuscript in Springer, should the article be accepted by the Editor-in-chief upon completion of the refereeing process.

Authors Contributions: Abdullah YILDIZBASI: Conceptualization, Methodology, Data curation, Writing - review \& editing., Supervision. Yagmur ARIOZ: Conceptualization, Data curation, Writing - original draft, Writing - review \& editing. 


\section{References}

Ara, Ekonomik. 2015. "Kuruluş Yeri Seçiminde Bulanık TOPSIS Yöntemi ve Bankacılık Sektöründe Bir Uygulama.” Karamanoğlu Mehmetbey Üniversitesi Sosyal Ve Ekonomik Araştırmalar Dergisi 2010 (1): 37-45. https://doi.org/10.18493/kmusekad.49220.

Awasthi, Anjali, Kannan Govindan, and Stefan Gold. 2017. "Multi-Tier Sustainable Global Supplier Selection Using a Fuzzy AHP-VIKOR Based Approach.” International Journal of Production Economics. https://doi.org/10.1016/j.ijpe.2017.10.013.

Badiezadeh, Taliva, Reza Farzipoor Saen, and Tahmoures Samavati. 2018. "Assessing Sustainability of Supply Chains by Double Frontier Network DEA: A Big Data Approach." Computers and Operations Research 98: 284-90. https://doi.org/10.1016/j.cor.2017.06.003.

Banaeian, Narges, Hossein Mobli, Behnam Fahimnia, Izabela Ewa Nielsen, and Mahmoud Omid. 2018. "Green Supplier Selection Using Fuzzy Group Decision Making Methods: A Case Study from the Agri-Food Industry." Computers and Operations Research 89: 33747. https://doi.org/10.1016/j.cor.2016.02.015.

Govindan, Kannan, T. C.E. Cheng, Nishikant Mishra, and Nagesh Shukla. 2018. "Big Data Analytics and Application for Logistics and Supply Chain Management." Transportation Research Part E: Logistics and Transportation Review 114 (May): 343-49. https://doi.org/10.1016/j.tre.2018.03.011.

Göksu, A., \& Güngör, İ. (2008). Fuzzy analytic hierarchy process and its application of university preference ranking. Suleyman Demirel University the Journal of Faculty of Economics and Administrative Sciences, 13(3), 1-26.

Gupta, Shubham, Umang Soni, and Girish Kumar. 2019. “Green Supplier Selection Using Multi-Criterion Decision Making under Fuzzy Environment: A Case Study in Automotive Industry." Computers and Industrial Engineering $136 \quad$ (140): 663-80. https://doi.org/10.1016/j.cie.2019.07.038.

Hashemi, Seyed Hamid, Amir Karimi, and Madjid Tavana. 2015. "An Integrated Green Supplier Selection Approach with Analytic Network Process and Improved Grey Relational Analysis." International Journal of Production Economics 159: 178-91. https://doi.org/10.1016/j.ijpe.2014.09.027.

İnce, Mehmet Enes. 2013. "Yeşil Tedarik Zinciri Yaklaşimi ve Örnekleri,” 1-14.

Kannan, Devika, Ana Beatriz Lopes De Sousa Jabbour, and Charbel José Chiappetta Jabbour. 2014. "Selecting Green Suppliers Based on GSCM Practices: Using Fuzzy TOPSIS Applied to a Brazilian Electronics Company." European Journal of Operational Research 233 (2): 432-47. https://doi.org/10.1016/j.ejor.2013.07.023.

Khalilzadeh, Mohammad, and Hadis Derikvand. 2018. "A Multi-Objective Supplier Selection Model for Green Supply Chain Network under Uncertainty." Journal of Modelling in Management 13 (3): 605-25. https://doi.org/10.1108/JM2-06-2017-0062.

Lee, Amy H I, He-Yau Kang, Chang-Fu Hsu, and Hsiao-Chu Hung. 2009. "A Green Supplier Selection Model for High-Tech Industry.” Expert Systems with Applications 36 (4): 7917 27. https://doi.org/http://dx.doi.org/10.1016/j.eswa.2008.11.052. 
Lee, Tzong Ru, Thi Phuong Nha Le, Andrea Genovese, and Lenny S.C. Koh. 2011. "Using FAHP to Determine the Criteria for Partner's Selection within a Green Supply Chain: The Case of Hand Tool Industry in Taiwan." Journal of Manufacturing Technology Management 23 (1): 25-55. https://doi.org/10.1108/17410381211196276.

Li, Qi, and Ang Liu. 2019. "Big Data Driven Supply Chain Management." Procedia CIRP 81: 1089-94. https://doi.org/10.1016/j.procir.2019.03.258.

Liu, Pan, and Shu-ping Yi. 2017. "Pricing Policies of Green Supply Chain Considering Targeted Advertising and Product Green Degree in the Big Data Environment." Journal of Cleaner Production 164: 1614-22. https://doi.org/10.1016/j.jclepro.2017.07.049.

Liu, Yumin, Linlin Jin, and Feng Zhu. 2019. "A Multi-Criteria Group Decision Making Model for Green Supplier Selection under the Ordered Weighted Hesitant Fuzzy Environment." Symmetry 11 (1). https://doi.org/10.3390/sym11010017.

Memari, A., Dargi, A., Akbari Jokar, M. R., Ahmad, R., \& Abdul Rahim, A. R. (2019). Sustainable supplier selection: A multi-criteria intuitionistic fuzzy TOPSIS method. Journal of Manufacturing Systems, 50(November 2018), 9-24. https://doi.org/10.1016/j.jmsy.2018.11.002.

Rashidi, Kamran, and Kevin Cullinane. 2019. "A Comparison of Fuzzy DEA and Fuzzy TOPSIS in Sustainable Supplier Selection: Implications for Sourcing Strategy." Expert Systems with Applications 121: 266-81. https://doi.org/10.1016/j.eswa.2018.12.025.

Roßmann, Bernhard, Angelo Canzaniello, Heiko von der Gracht, and Evi Hartmann. 2018. "The Future and Social Impact of Big Data Analytics in Supply Chain Management: Results from a Delphi Study." Technological Forecasting and Social Change 130 (October 2017): 135-49. https://doi.org/10.1016/j.techfore.2017.10.005.

Rouyendegh, Babak Daneshvar, Abdullah Y1ldıbbaş1, and Pelin Üstünyer. 2020. "Intuitionistic Fuzzy TOPSIS Method for Green Supplier Selection Problem.” Soft Computing 24: 221528. https://doi.org/10.1007/s00500-019-04054-8.

Shen, Lixin, Laya Olfat, Kannan Govindan, Roohollah Khodaverdi, and Ali Diabat. 2013. "A Fuzzy Multi Criteria Approach for Evaluating Green Supplier's Performance in Green Supply Chain with Linguistic Preferences." Resources, Conservation and Recycling 74: 170-79. https://doi.org/10.1016/j.resconrec.2012.09.006.

Sirisawat, Pornwasin, and Tossapol Kiatcharoenpol. 2018. "Fuzzy AHP-TOPSIS Approaches to Prioritizing Solutions for Reverse Logistics Barriers." Computers and Industrial Engineering 117 (January): 303-18. https://doi.org/10.1016/j.cie.2018.01.015.

Tang, Xiyue, and Guiwu Wei. 2018. "Models for Green Supplier Selection in Green Supply Chain Management with Pythagorean 2-Tuple Linguistic Information." IEEE Access 6: 18042-60. https://doi.org/10.1109/ACCESS.2018.2817551.

Torfi, Fatemeh, Reza Zanjirani Farahani, and Shabnam Rezapour. 2010. "Fuzzy AHP to Determine the Relative Weights of Evaluation Criteria and Fuzzy TOPSIS to Rank the Alternatives." Applied Soft Computing Journal $10 \quad$ (2): 520-28. https://doi.org/10.1016/j.asoc.2009.08.021.

Valmohammadi, Changiz, and Shahrbanoo Dashti. 2016. "Using Interpretive Structural Modeling and Fuzzy Analytical Process to Identify and Prioritize the Interactive Barriers 
of E-Commerce Implementation." Information and Management 53 (2): 157-68. https://doi.org/10.1016/j.im.2015.09.006.

Yazdani, M. (2014). An integrated MCDM approach to green supplier selection. International Journal of Industrial Engineering Computations, 5(3), 443-458. https://doi.org/10.5267/j.ijiec.2014.3.003

Yıldızbaşı, A., Öztürk, C., Efendioğlu, D., \& Bulkan, S. Assessing the social sustainable supply chain indicators using an integrated fuzzy multi-criteria decision-making methods: a case study of Turkey. Environment, Development and Sustainability, 1-36. https://doi.org/10.1007/s10668-020-00774-2

Wang, Gang, Angappa Gunasekaran, Eric W.T. Ngai, and Thanos Papadopoulos. 2016. "Big Data Analytics in Logistics and Supply Chain Management: Certain Investigations for Research and Applications." International Journal of Production Economics 176: 98-110. https://doi.org/10.1016/j.ijpe.2016.03.014.

Wu, Jinsong, Song Guo, Jie Li, and Deze Zeng. 2016. "Big Data Meet Green Challenges: Greening Big Data.” IEEE Systems Journal $10 \quad$ (3): 873-87. https://doi.org/10.1109/JSYST.2016.2550538.

Wu, Mei-Qin, Can-Hui Zhang, Xiao-Na Liu, and Jian-Ping Fan. 2019. "Green Supplier Selection Based on DEA Model in Interval-Valued Pythagorean Fuzzy Environment." IEEE Access 7: 108001-13. https://doi.org/10.1109/access.2019.2932770.

Zhao, Rui, Yiyun Liu, Ning Zhang, and Tao Huang. 2017. "An Optimization Model for Green Supply Chain Management by Using a Big Data Analytic Approach.” Journal of Cleaner Production 142: 1085-97. https://doi.org/10.1016/j.jclepro.2016.03.006.

Zhong, Ray Y., Stephen T. Newman, George Q. Huang, and Shulin Lan. 2016. "Big Data for Supply Chain Management in the Service and Manufacturing Sectors: Challenges, Opportunities, and Future Perspectives." Computers and Industrial Engineering 101: 57291. https://doi.org/10.1016/j.cie.2016.07.013. 
Figures

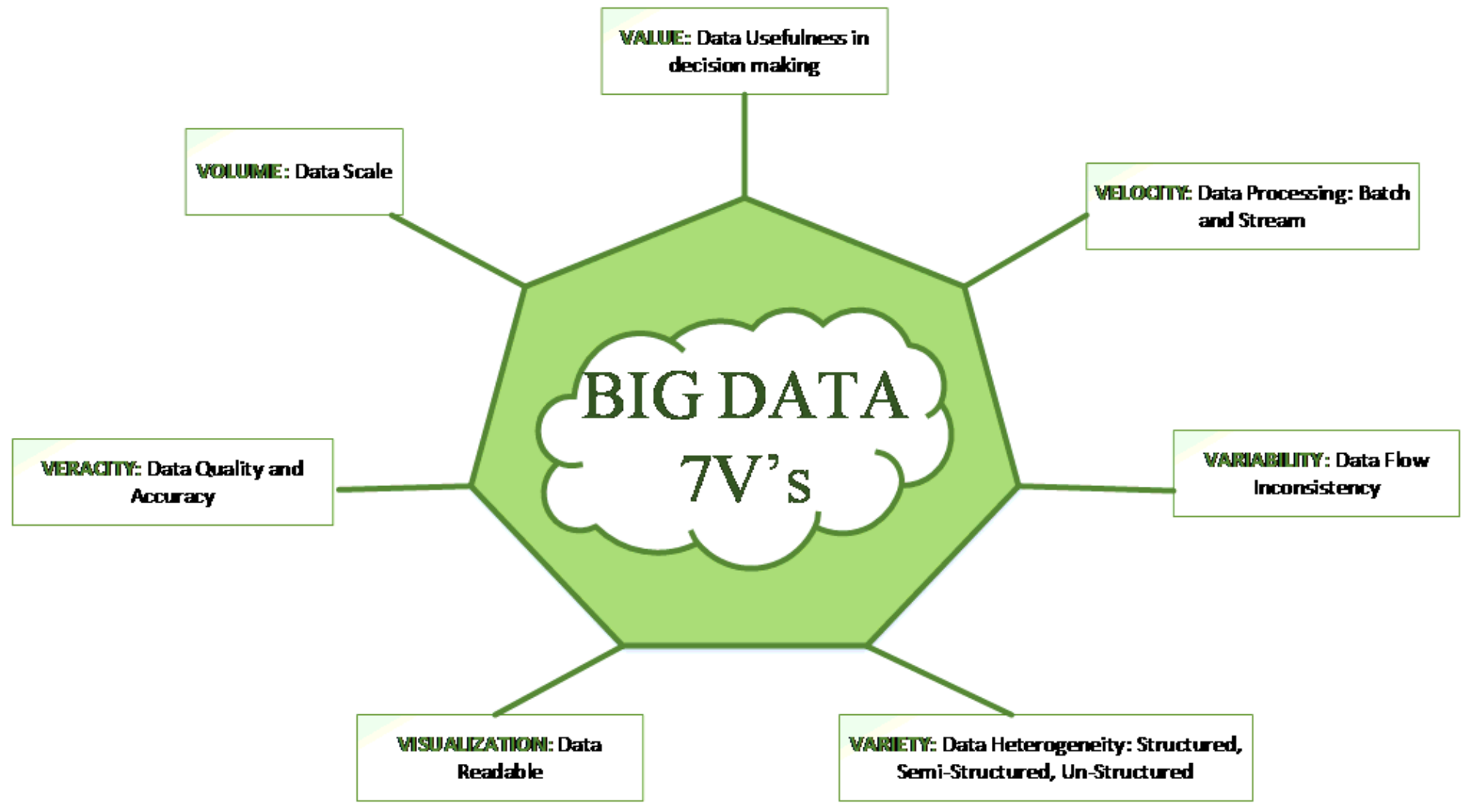

Figure 1

The 7V's characteristics of big data

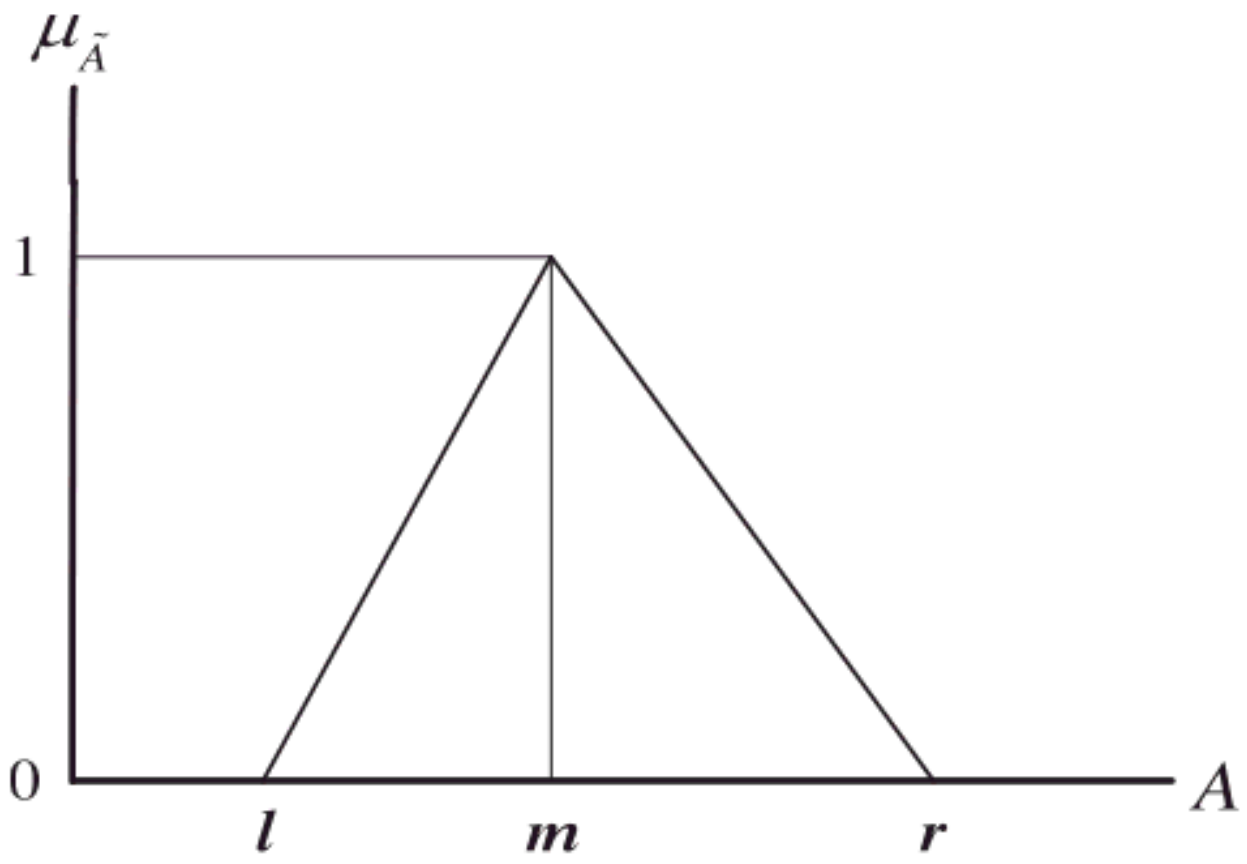

Figure 2 
A membership function of the triangular fuzzy number 